BMJ Open Diabetes

Research \& Care

\section{Pre-diabetes, diabetes and fluctuations of glucose tolerance after gestational diabetes mellitus: 5-year follow-up of a contemporary, prospective study in Germany}

To cite: Haschka SJ, Gar C, Sacco V, et al. Prediabetes, diabetes and fluctuations of glucose tolerance after gestational diabetes mellitus: 5 -year follow-up of a contemporary, prospective study in Germany. BMJ Open Diab Res Care 2022:10:e002621. doi:10.1136/ bmjdrc-2021-002621

- Additional supplemental material is published online only. To view, please visit the journal online (http://dx.doi. org/10.1136/bmjdrc-2021002621).

SJH and CG are joint first authors.

Received 4 October 2021 Accepted 29 January 2022

\section{Check for updates}

(c) Author(s) (or their employer(s)) 2022. Re-use permitted under CC BY-NC. No commercial re-use. See rights and permissions. Published by BMJ.

For numbered affiliations see end of article.

Correspondence to Dr Andreas Lechner; andreas.lechner@med.unimuenchen.de

\section{ABSTRACT}

Introduction Ten years ago, Germany started offering screening for gestational diabetes mellitus (GDM) to all pregnant women. This approach revealed more but also, on average, less severe cases of GDM than the risk-based screening practiced previously. We now examined the incidence of pre-diabetes and diabetes following a GDM diagnosis in the era of universal screening in Germany and compared our results with studies in the previous period. Additionally, we examined the year-to-year fluctuations of glucose tolerance after a pregnancy complicated by GDM. Research design and methods We report 5-year followup data from 202 women in the prospective, monocenter, postpartum study PPSDiab. Consecutive recruitment took place in Munich, Germany between 2011 and 2016. In the study, we conducted yearly examinations that included anthropometrics, laboratory chemistry and oral glucose tolerance testing.

Results During the first 5 years post partum, $111(55 \%)$ and $12(6 \%)$ of the women developed pre-diabetes and type 2 diabetes, respectively, while $2(1 \%)$ developed type 1 diabetes. Impaired fasting glucose (IFG) was the most common first manifestation of disturbed glucose tolerance, followed by impaired glucose tolerance (IGT), the combination of IFG and IGT, and diabetes. Glucose tolerance did not deteriorate steadily in most women but fluctuated from year to year.

Conclusions In our analysis, the incidence of diabetes, both type 1 and type 2, after GDM diagnosed in universal screening was substantially lower than in studies from the previous period of risk-based screening. Nevertheless, the high incidence of pre-diabetes we observed after GDM still confirms the importance of this diagnosis as a risk marker. Additionally, we documented frequent fluctuations of glucose tolerance from 1 year to the next. Therefore, a single postpartum glucose tolerance test, as currently practiced in routine care, may be insufficient for reliable risk stratification after GDM.

\section{Significance of this study}

What is already known about this subject?

- Women who had gestational diabetes mellitus (GDM) are at risk of also developing postpartum disturbances of glucose metabolism, that is, pre-diabetes and diabetes, mainly type 2 .

- Ten years ago, Germany started offering screening for GDM to all pregnant women. This approach increased the discovery rate of GDM but also resulted, on average, in the detection of milder forms of the disease.

What are the new findings?

- In comparison with German studies from the period before universal screening, we observed a substantially lower incidence of diabetes during 5 years after GDM; $6 \%$ for type 2 and $1 \%$ for type 1 diabetes.

- Nevertheless, $55 \%$ of the women in our study developed pre-diabetes indicating that a GDM diagnosis continues to be a risk marker for postpartum disturbances of glucose metabolism also in the era of universal screening.

- In most women, glucose tolerance did not deteriorate steadily over time but fluctuated from year to year.

How might these results change the focus of research or clinical practice?

- GDM still must be viewed as an important risk marke for postpartum disturbances of glucose metabolism. However, with universal screening, the short-term risk of overt diabetes is lower than suggested by studies from the previous period of risk-based screening.

\section{INTRODUCTION}

Women who develop gestational diabetes mellitus (GDM) are at high risk of subsequent, permanent diabetes, in particular type 2. A recent meta-analysis found a mean relative risk $(95 \% \mathrm{CI})$ of 9.51 (7.14 to 12.67$)$ for 
type 2 diabetes $1-25$ years after a pregnancy complicated by GDM, compared with a normoglycemic pregnancy. GDM serves as a risk marker for type 2 diabetes across many different countries and ethnicities. ${ }^{1}$ However, the relative risk $(95 \% \mathrm{CI})$ for type 2 diabetes in previous studies varied widely, between 2.19 (1.58 to 3.06) and 37.14 (2.25 to 612.55 ) during 15 years of follow-up. ${ }^{23}$ This variability may be explained by differences in the age, body mass index (BMI) and ethnicity of the women included in the studies, as well as by the location of the study site and the diagnostic criteria for GDM and type 2 diabetes. ${ }^{1}$ Variability between studies was found to be particularly high within European countries. ${ }^{4}$

Different screening strategies for GDM may also affect the postpartum metabolic risk associated with this diagnosis. In comparison with risk-based screening, universal screening of all pregnancies reveals more but, on average, less severe cases of GDM. ${ }^{5}$ These may be associated with a lower postpartum risk, but this issue has not yet been addressed in detail. In Germany, four previous studies reported the incidence of diabetes after GDM ${ }^{6-9}$ which ranged from $5.5 \%$ within the first year to $52.7 \%$ within 8 years post partum. ${ }^{6-10}$ Recruitment for these studies took place between 1989 and 2009 when screening for GDM was based on risk factors or clinical suspicion.

In 2011, Germany started offering screening for GDM to all pregnant women as part of prenatal care. ${ }^{11}$ The screening approach since then is usually two step, with a $50 \mathrm{~g}$ glucose challenge test followed by a full $75 \mathrm{~g}$ oral glucose tolerance test (OGTT) applying the International Association of the Diabetes and Pregnancy Study Groups (IADPSG) criteria. Before 2011, established risk factors that triggered testing for GDM were overweight/obesity $\left(\mathrm{BMI} \geq 27 \mathrm{~kg} / \mathrm{m}^{2}\right)$, gestational diabetes in prior pregnancies, diagnosed diabetes mellitus in parents or siblings, a previous child's birth weight $\geq 4500 \mathrm{~g}$, status post stillbirth, habitual abortions ( $\geq 3$ consecutive miscarriages), or major congenital deformities in a prior pregnancy.

Following this change, we started the PPSDiab ('Prediction, Prevention, and Subclassification of Type 2 Diabetes') Study, a prospective, postpartum cohort study. ${ }^{12}$ This study aims to provide a better understanding of pre-diabetes and type 2 diabetes after GDM. For this manuscript, we examined the 5-year follow-up data after a pregnancy complicated by GDM. We estimated incidence rates in the era of universal screening, evaluated yearly fluctuations of glucose tolerance and analyzed the changes in basic anthropometric and metabolic parameters between 1 and 5 years post partum. Therefore, we were also able to evaluate the validity of the current follow-up strategy after GDM in routine care, which, in Germany, mainly consists of a single OGTT. ${ }^{13}$

\section{MATERIAL AND METHODS}

Study cohort

The prospective, monocentric observational study PPSDiab included women who had GDM during their last pregnancy (post-GDM group) and women with a normoglycemic pregnancy (control group) in a 2:1 ratio. Participants were consecutively recruited between November 2011 and May 2016 from the diabetes center and the obstetrics department of the University Hospital, LMU Munich, Germany.

Women 3-16 months after a singleton $(n=295)$ or twin ( $\mathrm{n}=9)$ pregnancy with live birth(s) and with a valid glucose tolerance test during the pregnancy were included in the study. According to the German national guidelines, GDM was diagnosed by a $75 \mathrm{~g}$ OGTT with the cut-off values according to the IADPSG (plasma glucose: fasting $\geq 5.1 \mathrm{mmol} / \mathrm{L} \quad(92 \mathrm{mg} / \mathrm{dL}), 1$ hour $\geq 10.0 \mathrm{mmol} / \mathrm{L}(180 \mathrm{mg} / \mathrm{dL})$, and 2 hours $\geq 8.5 \mathrm{mmol} / \mathrm{L}$ $(153 \mathrm{mg} / \mathrm{dL}))$. Women with a normoglycemic pregnancy (normal $75 \mathrm{~g}$ OGTT according to the IADPSG criteria or a $50 \mathrm{~g}$ screening OGTT with a 1-hour plasma glucose $<7.5 \mathrm{mmol} / \mathrm{L}(135 \mathrm{mg} / \mathrm{dL})$ after the $23 \mathrm{rd}$ week of gestation) were included in the control group.

Exclusion criteria for this study were alcohol or substance abuse, pre-pregnancy diabetes, and chronic diseases requiring continuous medication, except for hypothyroidism $(\mathrm{n}=52)$, bronchial asthma $(\mathrm{n}=8)$, mild hypertension $(n=4)$, gastroesophageal reflux $(n=2)$, and history of pulmonary embolism resulting in rivaroxaban prophylaxis $(\mathrm{n}=1)$.

For this manuscript, we analyzed only the post-GDM group of women.

\section{Study visits}

The baseline visit of the PPSDiab Study was conducted 3-16 months after the index pregnancy. The 5-year follow-up visit was scheduled 58-66 months post partum. This visit was postponed if an additional pregnancy or the early postpartum phase ( 6 months post partum) overlapped during these months or if personal reasons or an intermittent illness $(\mathrm{n}=47$; median $(\mathrm{Q} 1-\mathrm{Q} 3)=70(68-74)$ months post partum) interfered.

Between the baseline and the 5-year follow-up visit, the women in the post-GDM group attended yearly in-person visits with an OGTT, whereas the women in the control group had yearly phone interviews. If an in-person visit could not be realized, a phone interview replaced it whenever possible. A diagnosis of diabetes during a study OGTT or otherwise ended study participation of the affected woman. For the remaining participants, PPSDiab is still ongoing.

\section{Oral glucose tolerance test}

At each in-person visit, we conducted a 5-point $75 \mathrm{~g}$ OGTT with measurements of plasma glucose and serum insulin at $0,30,60,90$ and $120 \mathrm{~min}$. According to the criteria of the American Diabetes Association, impaired fasting glucose (IFG) was defined as a fasting plasma glucose $\geq 100 \mathrm{mg} / \mathrm{dL}(5.6 \mathrm{mmol} / \mathrm{L})$, impaired glucose tolerance (IGT) as a 2-hour plasma glucose $\geq 140 \mathrm{mg}$ / $\mathrm{dL}(7.8 \mathrm{mmol} / \mathrm{L})$, and diabetes as fasting plasma glucose $\geq 126 \mathrm{mg} / \mathrm{dL}(7.0 \mathrm{mmol} / \mathrm{L})$, a 2-hour plasma glucose 
$\geq 200 \mathrm{mg} / \mathrm{dL}(11.0 \mathrm{mmol} / \mathrm{L})$, and $/$ or a glycated hemoglobin (HbAlc) of $\geq 6.5 \%(48 \mathrm{mmol} / \mathrm{mol}) .{ }^{14}$

\section{Biochemical measurements}

All blood samples, except for post-load glucose and insulin in the OGTT, were determined after an overnight fast. Plasma glucose was determined by the hexokinase method (Glucose HK Gen.3, Roche Diagnostics, Mannheim, Germany), serum insulin by a chemoluminescence immunoassay (DiaSorin LIASON systems, Saluggia, Italy), plasma HbA1c by high performance liquid chromatography (VARIANT II TURBO HbAlc Kit, Bio-Rad Laboratories, Hercules, USA), and serum blood lipids (high-density lipoprotein (HDL) cholesterol and triglycerides) by enzymatic caloric test (Roche Diagnostics, Mannheim, Germany). Low-density lipoprotein (LDL) cholesterol was calculated by the Friedewald equation.

\section{Anthropometrical measurements}

Body mass and composition were measured by bioelectrical impedance analysis (Tanita BC-418; Tanita Corporation, Tokyo, Japan). ${ }^{15}$ Height and waist circumference were determined using a tape measure to the nearest centimeter. Resting systolic and diastolic blood pressure in a seated position were calculated as the mean out of two measurements on the arm with the higher systolic value at baseline.

\section{Medical history}

Medical history was assessed by questionnaires. The selfreported data were reviewed by a study physician and any inconsistencies or uncertainties were corrected in consultation with the participant.

\section{Calculations}

Insulin sensitivity was calculated from the OGTT as the insulin sensitivity index (ISI) according to Matsuda and DeFronzo: ${ }^{16}$

ISI $=10 \quad 000 / \sqrt{ }\left[\left(\right.\right.$ glucose $\quad 0^{\prime} \times$ insulin $\left.\quad 0^{\prime}\right) \times($ glucose $0^{\prime}+2 \times\left(\right.$ glucose $\left.30^{\prime}+60^{\prime}+90^{\prime}\right)+$ glucose $\left.120^{\prime}\right) / 8 \times($ insulin $0^{\prime}+2 \times\left(\right.$ insulin $\left.30^{\prime}+60^{\prime}+90^{\prime}\right)+$ insulin $\left.\left.120^{\prime}\right) / 8\right]$.

In addition, the homeostasis model assessment of insulin resistance (HOMA-IR) was calculated according to Matthews et al: ${ }^{17}$

HOMA-IR=glucose $0^{\prime} \times$ insulin $00^{\prime} / 22.5$.

The disposition index (DI) was calculated as: ${ }^{18}$ $\mathrm{DI}=\mathrm{ISI} \times$ (insulin 30'-insulin $0^{\prime}$ ). The ISI was previously validated with data from intravenous glucose tolerance and euglycemic clamp tests in this cohort. ${ }^{19}$

\section{Statistical analysis}

All normally distributed metric variables are reported as mean $\pm \mathrm{SD}$; non-normally distributed metric variables are presented as median (first quartile-third quartile). Categorical variables are presented as frequency (percentage). For longitudinal comparisons of metric variables between the baseline and the 5-year follow-up visit, we applied paired t-tests for normally distributed and the Wilcoxon signed-rank test for non-normally distributed variables. $\mathrm{P}$ values of $<0.05$ were considered statistically significant. All statistical calculations were performed using SAS statistical software package V.9.4 (SAS Institute). The flow chart and alluvial plot were built using the draw.io app (http://diagrams.net) and rawgraphs.io, ${ }^{20}$ respectively. GraphPad Prism was used for further graphic representations (Survival table, GraphPad Prism V.6.0 for Mac, GraphPad Software, La Jolla, California, USA).

\section{RESULTS}

Of the 202 women included in the post-GDM group of the PPSDiab Study, 2 (1\%) developed type 1 diabetes and were therefore excluded from further analyses. The characteristics of the remaining 200 study participants at the baseline visit, which took place 3-16 months after delivery, are summarized in table 1.

Between the baseline and the 5-year follow-up visit, PPSDiab included yearly visits with OGTTs. The numbers of participating women at each visit and the OGTT results are presented in figure 1 and online supplemental table $\mathrm{S} 1$. At the baseline visit, seven women were diagnosed with type 2 diabetes. Another five women developed type 2 diabetes during follow-up, resulting in a total 5-year incidence of $12(6 \%)$. At the 5-year follow-up, 158 women $(78 \%)$ still participated in the study. Women who remained in the study did not differ significantly from those who dropped out in their major baseline characteristics (OGTT glucose values, ISI, HOMA-IR, DI, BMI, body fat percentage, systolic or diastolic blood pressure, HDL cholesterol, triglycerides, HbA1c, insulin-dependent and non-insulin-dependent gestational diabetes, weight gain during pregnancy, gestational age at diagnosis of gestational diabetes, or family history in terms of type 1, type 2 or gestational diabetes; data not shown).

Figure 2 depicts the cumulative incidence rates of type 2 diabetes and of the different forms of pre-diabetes. For each woman, only the first pathologic OGTT was counted. Overall, $61 \%$ of the women post-GDM had at least one pathologic OGTT. As illustrated in figure 3, some women progressed from normal glucose tolerance to IFG or IGT and then to combined IFG/IGT or type 2 diabetes over time. However, glucose tolerance did not follow a clear trend in most women but instead fluctuated between different categories.

Table 2 summarizes the intraindividual changes in basic metabolic parameters between baseline and 5 years post partum. Only BMI, waist circumference, fasting plasma glucose and triglycerides increased significantly, whereas systolic blood pressure decreased. The use of antihypertensive medicines remained unchanged during follow-up (data not shown).

\section{DISCUSSION}

In this contemporary study of women post-GDM in Germany, we found a 5-year incidence of $1 \%$ for type 1 and $6 \%$ for type 2 diabetes, both substantially lower 
Table 1 Baseline characteristics

\section{Baseline visit 3-16 months post partum}

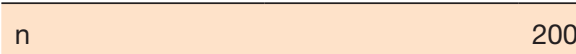

Time between delivery and baseline visit 38.4 (30.1-51.9)

(weeks)

(missing $\mathrm{n}=2$ )

\begin{tabular}{|c|c|c|}
\hline \multirow{5}{*}{$\begin{array}{l}\text { Status of glucose } \\
\text { metabolism }\end{array}$} & NGT & $124(63 \%)$ \\
\hline & IFG & $31(16 \%)$ \\
\hline & IGT & $23(12 \%)$ \\
\hline & IFG+IGT & $12(6 \%)$ \\
\hline & T2D & $7(3 \%)$ \\
\hline \multicolumn{2}{|c|}{ Fasting glucose (mg/dL) (missing $n=3$ ) } & $94.8 \pm 9.3$ \\
\hline \multicolumn{2}{|c|}{ 2-hour glucose (mg/dL) (missing $n=3$ ) } & $118(100-134)$ \\
\hline \multicolumn{2}{|l|}{ ISI (missing n=5) } & $4.5(2.9-6.8)$ \\
\hline \multicolumn{2}{|c|}{ HOMA-IR (missing $n=4$ ) } & $1.8(1.1-2.9)$ \\
\hline \multicolumn{2}{|l|}{ DI (missing $n=5$ ) } & $207.6(151.5-303.3)$ \\
\hline \multicolumn{2}{|c|}{ BMI $\left(\mathrm{kg} / \mathrm{m}^{2}\right)$ (missing $\left.\mathrm{n}=2\right)$} & $24.3(21.6-28.5)$ \\
\hline \multicolumn{2}{|c|}{ Waist circumference (cm) } & $79(73-88)$ \\
\hline \multicolumn{2}{|c|}{ Body fat percentage (\%) (missing $n=5$ ) } & $33.3 \pm 8.2$ \\
\hline \multicolumn{2}{|c|}{$\begin{array}{l}\text { Systolic blood pressure }(\mathrm{mm} \mathrm{Hg}) \\
(\text { missing } \mathrm{n}=1)\end{array}$} & $119 \pm 11$ \\
\hline \multicolumn{2}{|c|}{$\begin{array}{l}\text { Diastolic blood pressure }(\mathrm{mm} \mathrm{Hg}) \\
\text { (missing } n=1)\end{array}$} & $75 \pm 9$ \\
\hline \multicolumn{2}{|c|}{ HDL cholesterol (mg/dL) (missing $n=3$ ) } & $61.6 \pm 15.0$ \\
\hline \multicolumn{2}{|c|}{ Triglycerides (mg/dL) (missing $\mathrm{n}=3$ ) } & $70(56-98)$ \\
\hline \multicolumn{2}{|c|}{ HbA1c (NGSP) (\%) (missing $n=4$ ) } & $5.4 \pm 0.3$ \\
\hline \multicolumn{2}{|c|}{$\mathrm{HbA} 1 \mathrm{c}$ (IFCC) (mmol/mol) (missing $\mathrm{n}=4)$} & $35 \pm 4$ \\
\hline \multicolumn{2}{|c|}{ Spontaneous conception } & $175(87.5 \%)$ \\
\hline \multicolumn{2}{|c|}{ Medically assisted conception } & $25(12.5 \%)$ \\
\hline
\end{tabular}

First BMI documented in pregnancy $(\mathrm{kg} / 23.8$ (21.7-27.9)

$\mathrm{m}^{2}$ ) (missing $\mathrm{n}=2$ )

\begin{tabular}{|c|c|}
\hline Weight gain during pregnancy (kg) & $11.4 \pm 5.1$ \\
\hline Insulin treatment during pregnancy & $114(57 \%)$ \\
\hline $\begin{array}{l}\text { Gestational age at diagnosis of } \\
\text { gestational diabetes (weeks) }\end{array}$ & 27 (24-29) \\
\hline $\begin{array}{l}\text { Gestational week at the delivery (weeks) } \\
\text { (missing } n=2 \text { ) }\end{array}$ & $39.3(38.4-40)$ \\
\hline Maternal age at delivery (a) & $35 \pm 5$ \\
\hline Cesarean section & $60(30 \%)$ \\
\hline Birth weight (g) & $3362.5(3020-3615)$ \\
\hline APGAR 5 min (score $<9$ ) (missing $n=1$ ) & $9(4.5 \%)$ \\
\hline APGAR 10 min (score $<9$ ) (missing $n=1$ ) & $1(0.5 \%)$ \\
\hline Fetal morbidity & $24(12 \%)$ \\
\hline \multirow{3}{*}{$\begin{array}{l}\text { Breastfeeding } \\
\text { status (missing } n=4 \text { ) }\end{array}$} & $5(2.6 \%)$ \\
\hline & $15(7.7 \%)$ \\
\hline & $176(89.8 \%)$ \\
\hline $\begin{array}{l}\text { Family history of type } 1 \text { diabetes } \\
\text { (missing } n=4 \text { ) }\end{array}$ & $16(8.1 \%)$ \\
\hline $\begin{array}{l}\text { Family history of type } 2 \text { diabetes } \\
\text { (missing } n=4 \text { ) }\end{array}$ & 125 (63.5\%) \\
\hline
\end{tabular}

Continued

\section{Table 1 Continued}

\begin{tabular}{l} 
Baseline visit 3-16 months post partum \\
\hline $\begin{array}{l}\text { Family history of gestational diabetes } 18(9.1 \%) \\
\text { (missing } n=4)\end{array}$
\end{tabular}

Values are presented as mean $\pm \mathrm{SD}$, median (first-third quartile) or frequencies (\%).

$\mathrm{BMI}$, body mass index; $\mathrm{DI}$, disposition index; $\mathrm{HbA} 1 \mathrm{c}$, glycated hemoglobin; HDL, high-density lipoprotein; HOMA-IR, homeostasis model assessment of insulin resistance; IFCC, International Federation of Clinical Chemistry and Laboratory Medicine ; IFG, impaired fasting glucose; IGT, impaired glucose tolerance; ISI, insulin sensitivity index; NGSP, National Glycohemoglobin Standardization Program; NGT, normal glucose tolerance; T2D, type 2 diabetes.

than in studies from the previous period of risk-based screening for GDM. Nevertheless, we also determined a $55 \%$ incidence of pre-diabetes underscoring the role of GDM as a metabolic risk marker. Finally, we observed that glucose tolerance in yearly tests followed no linear trend in most women. Instead, fluctuations between different categories predominated.

Our first research question was to examine the incidence of diabetes after GDM in Germany diagnosed according to the latest national guideline, that is, through universal screening. In this examination, we found a substantially lower incidence of type 1 and of type 2 diabetes than in German studies from the previous period of risk-based screening for GDM. For example, Löbner $e t$ al stratify the risk of diabetes in a cohort of women with GDM who had been recruited between 1989 and 1999. ${ }^{10}$ They found an 8-year cumulative risk of postpartum diabetes of $52.7 \%$. From graphs in this publication, the diabetes risk after 5 years can be estimated at $10 \%$ in autoantibody-negative, diet-treated women with a BMI $<30 \mathrm{~kg} / \mathrm{m}^{2}$, at $65 \%$ in autoantibody-negative, insulin-treated women and at $90 \%$ in autoantibody-positive women. Hunger-Dathe et al reported on 237 women with GDM recruited between 1992 and 1999 and found cumulative risk of diabetes mellitus of $11.5 \%$ within 6 years after delivery (type 1 diabetes $2.3 \%$, type 2 diabetes $9.2 \%$ ). ${ }^{7}$ Another large-scale, multicenter study with women whose GDM was diagnosed between January 2000 and December 2005 in Germany, Schaefer-Graf et al found a diabetes prevalence of already $5.5 \%$ in OGTTs performed within 1year after delivery. ${ }^{9}$

However, consistent with our data, the incidence of type 2 diabetes in a contemporary Irish study, which also included women diagnosed by universal screening, was $2.2 \%$ with a mean follow-up of 2.6 years. ${ }^{21}$ Taken together, the 5-year risk of diabetes after GDM has probably been substantially overestimated by previous studies relying on risk-based screening. Nevertheless, the $55 \%$ incidence of pre-diabetes in our study confirms the importance of GDM as a metabolic risk marker. Overt diabetes may just take longer than 5 years to develop, as suggested by a recent Danish registry study. ${ }^{22}$ We also collected 5-year follow-up data from a group of 102women who had a normoglycemic pregnancy. The follow-up structure was different from the post-GDM group published here, but the results in this second group 


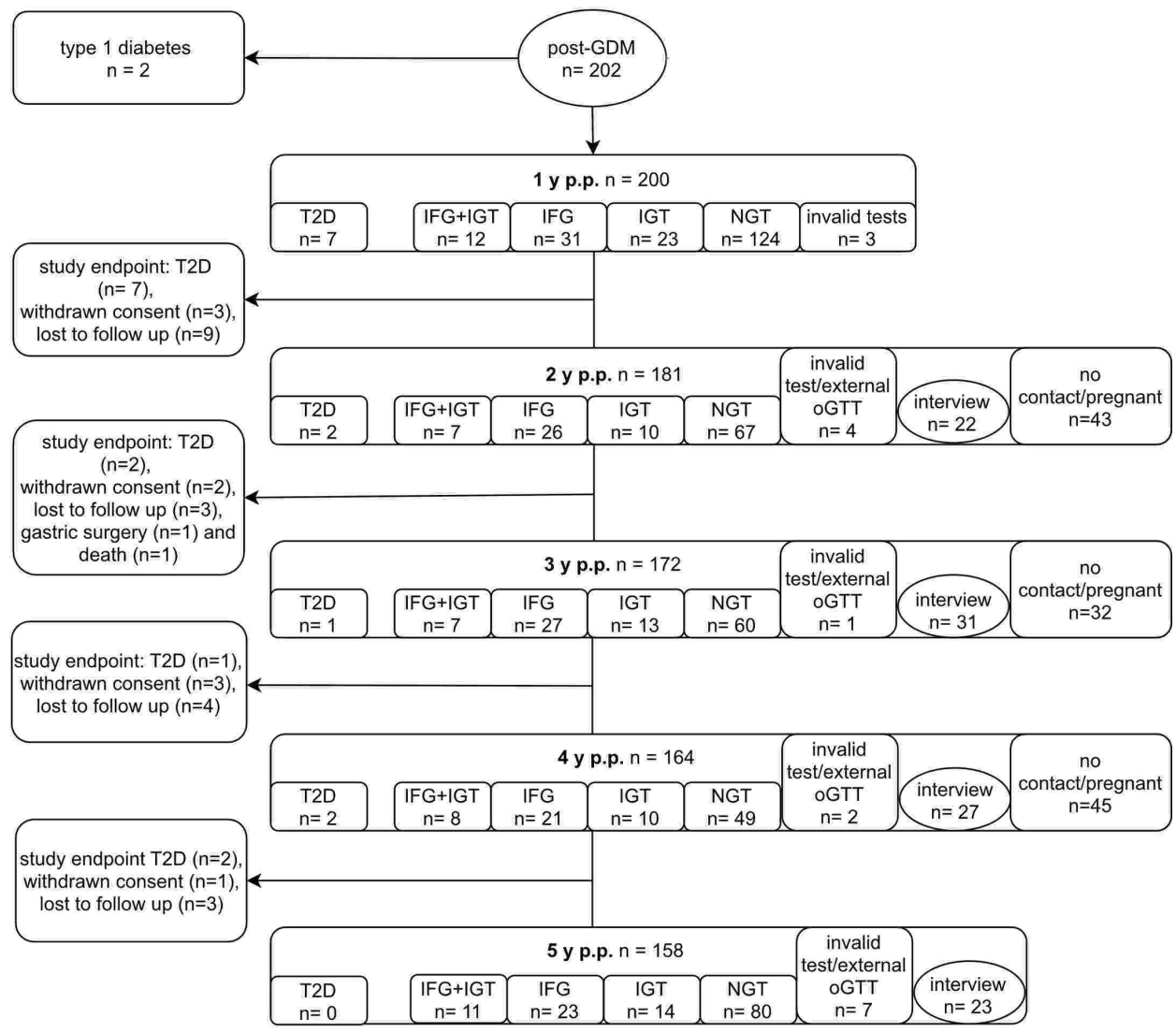

Figure 1 Flow chart of the 5-year follow-up of the PPSDiab Study. The primary study endpoint was defined as the diagnosis of type 2 diabetes (T2D) by OGTT. Participants during an additional pregnancy and up to 6 months post partum (p.p.) did not attend study visits for OGTT. GDM, gestational diabetes mellitus; IFG, impaired fasting glucose; IGT, impaired glucose tolerance; NGT, normal glucose tolerance; OGTT, oral glucose tolerance test.

can nevertheless serve as an approximate reference for the contemporary pre-diabetes and diabetes risk without a GDM diagnosis. At 5 years, $83 \%$ of the women had a normal OGTT, $17 \%$ had pre-diabetic values and none of the women had developed diabetes (data not shown).

Our second research question addressed the intraindividual fluctuations between categories of glucose

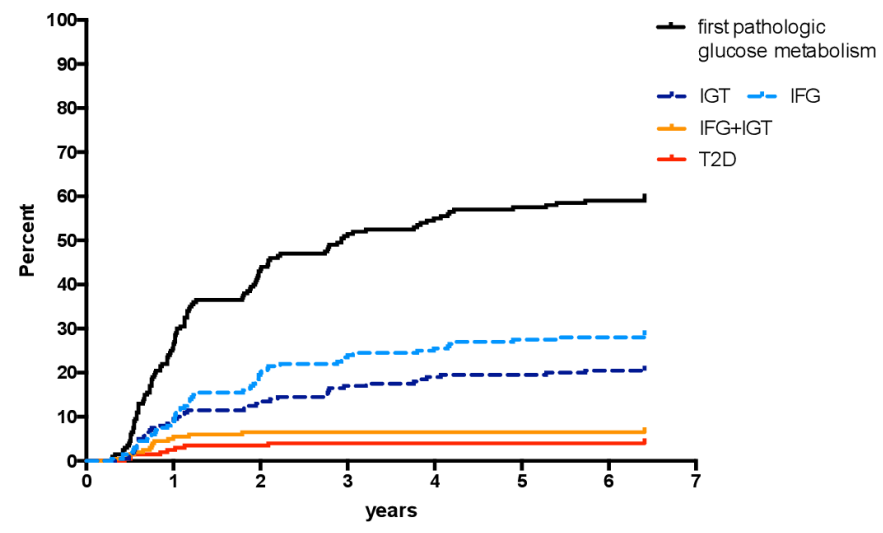

Figure 2 Cumulative incidence of pathologic OGTT results during 5 years post partum. Only the first pathologic test was counted for each woman. The black line represents the total count of all categories. IFG, impaired fasting glucose; IGT, impaired glucose tolerance; OGTT, oral glucose tolerance test; T2D, type 2 diabetes. tolerance over time. We found that fluctuations were common, with the OGTT results of most women not following clear trends. As we had shown previously in the PPSDiab Study, this is also the case for women with another pregnancy during follow-up, which does not alter glucose metabolism in the short term. ${ }^{23}$ Our observations correspond to population-based cohort

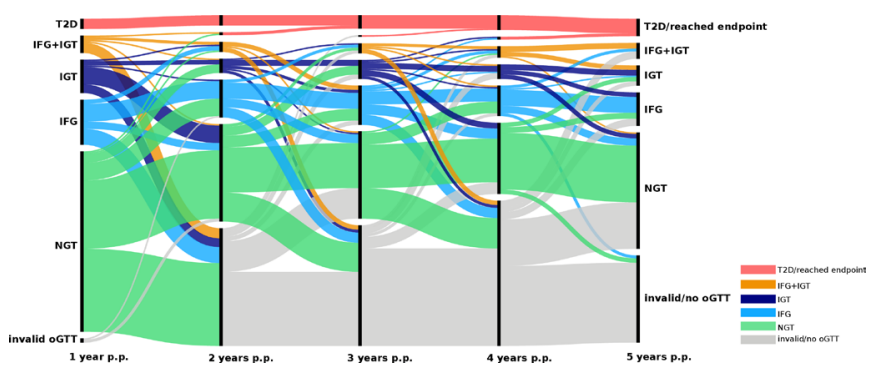

Figure 3 Intraindividual fluctuations of glucose tolerance during 5 years post partum (p.p.). Vertical bars mark the yearly study visits. Colors represent the status of glucose metabolism with green=normal glucose tolerance (NGT), light blue=isolated impaired fasting glucose (IFG), dark blue=isolated impaired glucose tolerance (IGT), orange=combined IFG and IGT (IFG+IGT), red=type 2 diabetes (T2D) equivalent to study endpoint, gray=invalid or no OGTT. Line width represents the number of participants following each trajectory. OGTT, oral glucose tolerance test. 
Table 2 Comparison of metabolic parameters at baseline and at the 5-year follow-up visit $(n=131)$

\begin{tabular}{|c|c|c|c|}
\hline & $\begin{array}{l}\text { Baseline visit 3-16 months post } \\
\text { partum }\end{array}$ & $\begin{array}{l}\text { Five-year follow-up visit or visit of T2D } \\
\text { diagnosis }\end{array}$ & $P$ value \\
\hline Fasting glucose (mg/dL) & $93.5 \pm 7.5$ & $96.0 \pm 9.5$ & $<0.001$ \\
\hline 2-hour glucose (mg/dL) & $\begin{array}{l}117 \\
(100-133)\end{array}$ & $\begin{array}{l}112 \\
(96-134)\end{array}$ & 0.604 \\
\hline ISI (missing $n=2$ ) & $\begin{array}{l}4.6 \\
(2.98-7.08)\end{array}$ & $\begin{array}{l}4.5 \\
(2.81-6.30)\end{array}$ & 0.112 \\
\hline HOMA-IR (missing $n=1$ ) & $\begin{array}{l}1.7 \\
(1.08-2.89)\end{array}$ & $\begin{array}{l}1.8 \\
(1.11-3.05)\end{array}$ & 0.134 \\
\hline $\mathrm{DI}$ (missing $\mathrm{n}=2$ ) & 203.8 (151.5-299.1) & $\begin{array}{l}215.8 \\
(161.6-265.8)\end{array}$ & 0.671 \\
\hline BMI $\left(\mathrm{kg} / \mathrm{m}^{2}\right)$ (missing $\left.\mathrm{n}=4\right)$ & $\begin{array}{l}23.6 \\
(21.38-27.80)\end{array}$ & $\begin{array}{l}23.9 \\
(21.5-27.7)\end{array}$ & 0.009 \\
\hline Waist circumference $(\mathrm{cm})$ (missing $\mathrm{n}=6$ ) & $78(73-86)$ & $80(74-88)$ & 0.019 \\
\hline Body fat percentage (\%) (missing $n=3$ ) & $32.2 \pm 8$ & $32.5 \pm 8.2$ & 0.338 \\
\hline Triglycerides (mg/dL) (missing $\mathrm{n}=2$ ) & $68(53-91)$ & $77(58-109)$ & 0.004 \\
\hline HbA1c (NGSP) (\%) (missing n=2) & $5.4 \pm 0.3$ & $5.4 \pm 0.3$ & 0.921 \\
\hline HbA1c (IFCC) (mmol/mol) (missing n=2) & $35 \pm 3$ & $35 \pm 4$ & 0.865 \\
\hline
\end{tabular}

Participants with a diagnosis of T2D at baseline $(n=7)$ and participants with an invalid OGTT or an OGTT not performed under our supervision (external) at baseline/the 5 -year followup $(n=9)$ were excluded from this table to permit paired testing. The 5 -point OGTT was invalid if a measurement of glucose and insulin was not possible at every time point $(0,30,60$, 90 and $120 \mathrm{~min}$ ). Participants were excluded likewise after loss to follow-up $(n=19)$, when their consent was withdrawn $(n=9)$, after relevant surgery or death $(n=2)$ or if they were only interviewed and not tested at 5-year follow-up $(n=23)$. For the five women who developed T2D between 1 and 5 years, their final study visit, at which diabetes was diagnosed, was included in this table. Values are presented as mean \pm SD, median (first-third quartile) or frequencies (\%). P values less than 0.05 are in bold. Time points were compared by paired t-test or Wilcoxon signed-rank test.

BMI, body mass index; DI, disposition index; HbA1c, glycated hemoglobin; HDL, high-density lipoprotein; HOMA-IR, homeostasis model assessment of insulin resistance; IFCC, International Federation of Clinical Chemistry and Laboratory Medicine; ISI, insulin sensitivity index; NGSP, National Glycohemoglobin Standardization Program; OGTT, oral glucose tolerance test; T2D, type 2 diabetes.

studies with yearly testing, where mean plasma glucose only increases steadily during the final 5 years prior to a diagnosis of type 2 diabetes. ${ }^{24-29}$ Since a steep rise of the incidence of type 2 diabetes is not expected before 12 years after GDM, ${ }^{22}$ the metabolic fluctuations observed in our analysis are unsurprising. Consequently, a single postpartum OGTT, as currently practiced in routine care in Germany and other countries, may not accurately represent a woman's metabolic status and thus her risk of future diabetes. Thus, women with a normal postpartum OGTT should be tested again $3-5$ years later.

Our third research question addressed the intraindividual changes of basic anthropometric and metabolic parameters between 1 and 5 years post-GDM. Here, BMI, waist circumference, fasting plasma glucose, and triglycerides increased, potentially underscoring the link between a previous GDM and the development of metabolic syndrome. ${ }^{30}$ However, systolic blood pressure decreased despite unchanged use of antihypertensive medications. The reason for this positive trend remains unclear.

The strengths of this study include its consecutively recruited cohort that is based on universal screening for GDM, which allowed for contemporary risk estimates. Additionally, the dropout rate was low, and, by yearly glucose tolerance testing, we were able to map intraindividual fluctuations of glucose tolerance. Moreover, there was no difference between those who stayed in the study and those who dropped out in terms of their most important baseline characteristics. However, the yearly testing regime is also a possible weakness of this study, as it may have constituted an unplanned intervention. It may have motivated the participating women to intensify lifestyle measures. Furthermore, the study design was not fully parallel to the previous German studies interrogated for comparison. Some bias may have been introduced by these differences. Finally, the results presented are only valid for Caucasian populations because multi-ethnic recruitment was not possible in the setting of this project.

In conclusion, our study demonstrates that the 5-year incidence of diabetes after GDM diagnosed in the era of universal screening is substantially lower than suggested by earlier studies. Nevertheless, our results confirm the importance of GDM as a metabolic risk marker. Universal screening for GDM therefore is not only an important component of prenatal care but also a unique public health opportunity. With respect to the mother's longterm health risks, this opportunity remains underused. In particular, our data reveal the dynamic nature of glucose tolerance after GDM. Therefore, the current practice of a single postpartum OGTT is probably insufficient for full risk estimation. Optimized, cost-effective follow-up schemes after GDM should thus be developed.

Author affiliations

${ }^{1}$ Diabetes Research Group, LMU Klinikum; Medizinische Klinik und Poliklinik IV, Munich, Germany 
${ }^{2}$ Clinical Cooperation Group Type 2 Diabetes, Helmholtz Zentrum München; German Research Center for Environmental Health, Neuherberg, Germany

${ }^{3}$ German Center for Diabetes Research, Neuherberg, Germany

Acknowledgements We thank all participants in the PPSDiab Study who made this work possible. We also thank Marietta Rottenkolber and Denise Kohn for their contribution to design and data management of the PPSDiab Study.

Contributors Conceptualization-SJH, CG, and AL. Formal analysis-CG. Investigation-SJH, CG, VS, FB, UF, IF, SK-M, AP, LUF, MM, IB, CT and AL. Data curation-SJH, CG and AL. Writing (original draft)—CG. Writing (review and editing)—all. Visualization—SJH. Supervision—JS and AL. Project administration-AL. Funding acquisition-AL and JS. AL is the guarantor of this work. This work was not published previously.

Funding This work was funded by the University Hospital, LMU Munich and Helmholtz Center Munich, Germany, and the German Center for Diabetes Research.

Competing interests None declared.

Patient consent for publication Not required.

Ethics approval This study involves human participants and was approved by Ethikkommission der Medizinischen Fakultaet der LMU Muenchen; Munich, Germany (reference number 300/11). Participants gave informed consent to participate in the study before taking part.

Provenance and peer review Not commissioned; externally peer reviewed.

Data availability statement Data are available upon reasonable request. Data are deidentified participant data and are available upon request. Please contact the corresponding author: Prof Dr A Lechner, andreas.lechner@med.uni-muenchen.de.

Supplemental material This content has been supplied by the author(s). It has not been vetted by BMJ Publishing Group Limited (BMJ) and may not have been peer-reviewed. Any opinions or recommendations discussed are solely those of the author(s) and are not endorsed by BMJ. BMJ disclaims all liability and responsibility arising from any reliance placed on the content. Where the content includes any translated material, BMJ does not warrant the accuracy and reliability of the translations (including but not limited to local regulations, clinical guidelines, terminology, drug names and drug dosages), and is not responsible for any error and/or omissions arising from translation and adaptation or otherwise.

Open access This is an open access article distributed in accordance with the Creative Commons Attribution Non Commercial (CC BY-NC 4.0) license, which permits others to distribute, remix, adapt, build upon this work non-commercially, and license their derivative works on different terms, provided the original work is properly cited, appropriate credit is given, any changes made indicated, and the use is non-commercial. See: http://creativecommons.org/licenses/by-nc/4.0/.

ORCID iDs

Cornelia Then http://orcid.org/0000-0001-5180-1973

Andreas Lechner http://orcid.org/0000-0002-0276-291X

\section{REFERENCES}

1 Vounzoulaki E, Khunti K, Abner SC, et al. Progression to type 2 diabetes in women with a known history of gestational diabetes systematic review and meta-analysis. BMJ 2020;369:m1361.

2 Minooee S, Ramezani Tehrani F, Rahmati M, et al. Diabetes incidence and influencing factors in women with and without gestational diabetes mellitus: a 15year population-based follow-up cohort study. Diabetes Res Clin Pract 2017;128:24-31.

3 Linné Y, Barkeling B, Rössner S. Natural course of gestational diabetes mellitus: long term follow up of women in the SPAWN study. BJOG 2002;109:1227-31.

4 Zhu Y, Zhang C. Prevalence of gestational diabetes and risk of progression to type 2 diabetes: a global perspective. Curr Diab Rep 2016;16:7.

5 Matta-Coelho C, Monteiro AM, Fernandes V, et al. Universal vs. riskfactor-based screening for gestational diabetes-an analysis from a 5-year Portuguese cohort. Endocrine 2019;63:507-12.

6 Hummel S, Much D, Rossbauer M, et al. Postpartum outcomes in women with gestational diabetes and their offspring: POGO study design and first-year results. Rev Diabet Stud 2013;10:49-57.

7 Hunger-Dathe W, Mosebach N, Sämann A, et al. Prevalence of impaired glucose tolerance 6 years after gestational diabetes. Exp Clin Endocrinol Diabetes 2006;114:11-17.
8 Köhler M, Ziegler AG, Beyerlein A. Development of a simple tool to predict the risk of postpartum diabetes in women with gestational diabetes mellitus. Acta Diabetol 2016;53:433-7.

9 Schaefer-Graf UM, Klavehn S, Hartmann R, et al. How do we reduce the number of cases of missed postpartum diabetes in women with recent gestational diabetes mellitus? Diabetes Care 2009;32:1960-4.

10 Löbner K, Knopff A, Baumgarten A, et al. Predictors of postpartum diabetes in women with gestational diabetes mellitus. Diabetes 2006;55:792-7.

11 Bekanntmachung eines Beschlusses des Gemeinsamen Bundesausschusses über eine Änderung der Richtlinien über die ärztliche Betreuung während der Schwangerschaft und nach der Entbindung (Mutterschafts-Richtlinien): Einführung eines Screenings auf Gestationsdiabetes [press release] 2012.

12 Gar C, Rottenkolber M, Grallert H, et al. Physical fitness and plasma leptin in women with recent gestational diabetes. PLoS One 2017;12:e0179128.

13 S3-Leitlinie Gestationsdiabetes mellitus (GDM), Diagnostik, Therapie und Nachsorge 2. Auflage [press release] 2018.

14 American Diabetes Association. 2. Classification and Diagnosis of Diabetes: Standards of Medical Care in Diabetes-2019. Diabetes Care 2019;42:S13-S28.

15 Bosy-Westphal A, Later W, Hitze B, et al. Accuracy of bioelectrical impedance consumer devices for measurement of body composition in comparison to whole body magnetic resonance imaging and dual X-ray absorptiometry. Obes Facts 2008;1:319-24.

16 Matsuda M, DeFronzo RA. Insulin sensitivity indices obtained from oral glucose tolerance testing: comparison with the euglycemic insulin clamp. Diabetes Care 1999;22:1462-70.

17 Matthews DR, Hosker JP, Rudenski AS, et al. Homeostasis model assessment: insulin resistance and beta-cell function from fasting plasma glucose and insulin concentrations in man. Diabetologia 1985;28:412-9.

18 Kahn SE, Prigeon RL, McCulloch DK, et al. Quantification of the relationship between insulin sensitivity and beta-cell function in human subjects. Evidence for a hyperbolic function. Diabetes 1993;42:1663-72.

19 Rottenkolber M, Ferrari U, Holland L, et al. The diabetes risk phenotype of young women with recent gestational diabetes. J Clin Endocrinol Metab 2015;100:E910-8.

20 Mauri M, Elli T, Caviglia G. RAWGraphs: a visualisation platform to create open outputs. Proceedings of the 12th Biannual Conference on Italian SIGCHI Chapter: ACM, 2017.

21 Noctor E, Crowe C, Carmody LA, et al. Abnormal glucose tolerance post-gestational diabetes mellitus as defined by the International association of diabetes and pregnancy study groups criteria. Eur J Endocrinol 2016;175:287-97.

22 Aagaard KA, Al-Far HM, Piscator U, et al. Manifest diabetes after gestational diabetes: a double-cohort, long-term follow-up in a Danish population. Arch Gynecol Obstet 2020;302:1271-8.

23 Fueessl LU, Rottenkolber M, Gar C, et al. No deleterious effect of an additional pregnancy on glucose metabolism in women with previous gestational diabetes mellitus. Diabetes Res Clin Pract 2021;171:108543.

24 Heianza Y, Arase Y, Fujihara K, et al. Longitudinal trajectories of $\mathrm{HbA} 1 \mathrm{c}$ and fasting plasma glucose levels during the development of type 2 diabetes: the Toranomon Hospital health management center study 7 (topics 7). Diabetes Care 2012;35:1050-2.

25 Hulman A, Simmons RK, Brunner EJ, et al. Trajectories of glycaemia, insulin sensitivity and insulin secretion in South Asian and white individuals before diagnosis of type 2 diabetes: a longitudinal analysis from the Whitehall II cohort study. Diabetologia 2017;60:1252-60.

26 Hulsegge G, Spijkerman AMW, van der Schouw YT, et al. Trajectories of metabolic risk factors and biochemical markers prior to the onset of type 2 diabetes: the population-based longitudinal Doetinchem study. Nutr Diabetes 2017;7:e270.

27 Oka R, Shibata K, Sakurai M, et al. Trajectories of Postload plasma glucose in the development of type 2 diabetes in Japanese adults. $J$ Diabetes Res 2017;2017:1-7.

28 Tabák AG, Jokela M, Akbaraly TN, et al. Trajectories of glycaemia, insulin sensitivity, and insulin secretion before diagnosis of type 2 diabetes: an analysis from the Whitehall II study. Lancet 2009;373:2215-21.

29 Tura A, Grassi A, Winhofer Y, et al. Progression to type 2 diabetes in women with former gestational diabetes: time trajectories of metabolic parameters. PLoS One 2012;7:e50419.

30 Tranidou A, Dagklis T, Tsakiridis I, et al. Risk of developing metabolic syndrome after gestational diabetes mellitus - a systematic review and meta-analysis. J Endocrinol Invest 2021;44:1139-1149. 